\title{
An Index Weighting Method of Integrating Analytic Hierarchy Process and Rough Set
}

\author{
Xue Qing, \\ Simulation Center \\ Academy of Armored Force Engineering \\ Beijing, China \\ xue_qing@yeah.net \\ Zheng Changwei ,Liu Yonghong \\ Simulation Center \\ Academy of Armored Force Engineering \\ Beijing, China
}

\author{
$\mathrm{Hu} \mathrm{Tao}$ \\ Simulation Center \\ Academy of Armored Force Engineering \\ Beijing, China \\ hu1606@yahoo.com.cn
}

\begin{abstract}
In order to solve some problems in index weighting method, this paper combined subjective judgment matrix of Analytic Hierarchy Process (AHP) with objective matrix based on rough set to get the combined judgment matrix, and calculated the weight of combined Judgment. Example showed that the method was reasonable and effective.
\end{abstract}

Keywords-AHP, rough set, index weighting

\section{INTRODUCTION}

Weight is the quantitative distribution of the importance of something or elements [1]. Weight is a important information of Evaluation, often used in multi-objective decision making, multi-index evaluation and prediction. Index weighting is giving corresponding weight to each index in the evaluation system, and it is an important part of the calculation process of evaluation. Usually, index weighting take a set of indexes for the study, included in the evaluation system, to research the relative importance of each index, and calculate the corresponding value.

The current method of determining weight can be divided into four categories, namely subjective weighting method, objective weighting method, weighting method integrating subjective and objective and the variable weight method [2-8]. This paper used a method of building combined judgment matrix and calculating its weight vector matrix to determine the weight of each index.

\section{INDEX WEIGHTING BASED ON AHP}

AHP is a new decision-making way of thinking from qualitative break to quantitative analysis and quantitative synthesis proposed in the mid 70 s of last century by T. L. Satty, an U.S. operation researcher [9]. It helps people to maintain the consistency of the thinking progress, and provides the analysis, prediction, evaluation, decisionmaking of complex systems a quantitative basis easy to be accepted.

The general steps of determining weight by AHP are:

1) Establish hierarchical structure
Analyze the relationship, logic adscription and importance between each factor, and arrange them to make up a top-down.

2) Determine quantitatively scale of thinking judgment

In order to achieve the transformation from qualitative to quantitative, this paper used index scale (Table.2), which meets the law of Weber - Fechner psychology and has a lot of good nature, be widely used in practice [10].

3)Construct pairwise comparison judgment matrix

Compare indexes with each other in the same layer, getting the judgment matrix $A=($ aij $) n \times n$. Matrix $A$ has the following properties: (1) aij $>0$; (2) aij=1/aji; (3) aii=1.

4) Calculate the relative weight

Eigenvector $\omega=(\omega 1, \omega 2, \cdots, \omega n)(\Sigma \omega i=1)$ normalized corresponding to feature value $\mathrm{n}$ of Matrix A reflects the weights of $n$ factors $x=\{x 1, x 2, \cdots, x n\}$ in the target, known as weight vector of factor $x$ to the target, and $\omega 1, \omega 2, \cdots, \omega n$ are the weights corresponding to each index.

5) Check consistency

Defined consistency ratio $\mathrm{CR}=\mathrm{CI} / \mathrm{RI}$, if $\mathrm{CR}<0.1$, generally considered the consistency of judgment matrix is acceptable. Where $C I=(\lambda-n) /(n-1)$ is the consistency index, $\lambda$ is the feature root, $\mathrm{n}$ is the order of A. RT is the random consistency index introduced by Saaty. Gong Musen and Xu Shubai [9] derived the 1-15 order average random consistency index counting 1000 times shown in Table.2:

If the judgment matrix can't pass test, it need to be restructured.

\section{INDEX WEIGHTING BASED ON ROUGH SET}

Rough set (RS) theory is a data analysis theory proposed by the Polish mathematician Pawlak in 1982, commonly used in dealing with fuzzy and imprecise problems. In recent years, rough set theory began to be used in multi-index comprehensive evaluation[11].

\section{A. The Basic Concepts of Rough Set Theory [12]}

Definition 1 An information system $\mathrm{S}$ can be expressed as ordered quadruple $\mathrm{S}=\{\mathrm{U}, \mathrm{R}, \mathrm{V}, \mathrm{f}\}$, where $\mathrm{U}$ is the domain, which is the set of all samples; $R=C \cup D$ is an attribute set, in which subset $\mathrm{C}$ is the condition attribute set, reflecting the characteristics of the object, D is decision attribute set, 
reflecting the class of the object; $\mathrm{V}=\cup \mathrm{Vr}(\mathrm{r} \in \mathrm{R})$ is the set of the attribute value, $\mathrm{Vr}$ indicates the range of attribute value; $\mathrm{f}: \mathrm{U} \times \mathrm{R} \rightarrow \mathrm{V}$ is the information function to determine the attribute value of each object in $U$, that is if either $x i \in U$, $\mathrm{r} \in \mathrm{R}$, then $\mathrm{f}(\mathrm{xi}, \mathrm{r})=\mathrm{Vr}$.

Definition 2 In the information system $\mathrm{S}$, for any subset of attributes $B \subseteq R$, if the object $\mathrm{xi}, \mathrm{xj} \in \mathrm{U}, \forall r \in B$, if and only if $\mathrm{f}(\mathrm{xi}, \mathrm{r})=\mathrm{f}(\mathrm{xj}, \mathrm{r})$, $\mathrm{xi}$ and $\mathrm{xj}$ is not distinguishable, denoted by Ind(B). Indiscernibility relation also called equivalence relation.

\section{B. Index Weighting Based on Attribute Importance [12]}

In rough set, each attribute has different importance, mainly reflect the classification of the information system. If remove an attribute can make a greater impact to the classification of a information system, indicating the high importance of the attribute; on the other hand showing the low importance of the attribute. Here introduce amount of information to express the changes in the classification.

Let information system $\mathrm{S}=\{\mathrm{U}, \mathrm{R}, \mathrm{V}, \mathrm{f}\}$, for the equivalence relation $\mathrm{P} \subseteq \mathrm{R}$ has a category $\mathrm{U} / \mathrm{Ind}(\mathrm{P})=\{\mathrm{X} 1$, $\mathrm{X} 2, \cdots, \mathrm{Xn}\}$, then the amount of information of $\mathrm{P}$ is:

$$
I(P)=\sum_{i=1}^{n} \frac{\left|X_{i}\right|}{|U|}\left[1-\frac{\left|X_{i}\right|}{|U|}\right]=1-\frac{1}{|U|^{2}} \sum_{i=1}^{n}\left|X_{i}\right|^{2}
$$

Where, $|\mathrm{Xi}|,|\mathrm{U}|$ are the base of collection (number of elements in the collection).

Attribute importance can be expressed by the concept of amount of information. Here use importance to measure the change of amount of information, the importance of attribute $r$ in the attribute set $P$ is defined as:

$$
\text { sigp- }\{\mathrm{r}\}(\mathrm{r})=\mathrm{I}(\mathrm{P})-\mathrm{I}(\mathrm{P}-\{\mathrm{r}\})
$$

Normalize the importance of each attribute, you can get the weight of each index. Such as $\mathrm{r} \in \mathrm{P}=\{\mathrm{r} 1, \mathrm{r} 2, \cdots, \mathrm{rn}\}$, the weight of index ri is:

$$
\omega_{r_{i}}=\frac{\operatorname{sig}_{P-\left\{r_{i}\right\}}\left(r_{i}\right)}{\sum_{j=1}^{n} \operatorname{sig}_{P-\left\{r_{i}\right\}}\left(r_{i}\right)}=\frac{I(P)-I\left(P-\left\{r_{i}\right\}\right)}{n I(P)-\sum_{j=1}^{n} I\left(P-\left\{r_{i}\right\}\right)}
$$

\section{COMPREHENSIVE INDEX WEIGHTING}

Let $A=($ aij) is subjective judgment matrix (has passed consistency test) obtained by the AHP, $i, j=1,2, \cdots, n$.

Let information system $\mathrm{S}=\{\mathrm{U}, \mathrm{R}, \mathrm{V}, \mathrm{f}\}, \mathrm{r} \in \mathrm{P}=\{\mathrm{r} 1$, $\mathrm{r} 2, \cdots, \mathrm{rn}\}, \mathrm{P}$ is the equivalence relation in $\mathrm{R}$. $\mathrm{B}=(\mathrm{bij}) \mathrm{n} \times \mathrm{n}$ is subjective judgment matrix obtained by rough set. Where:

$$
b_{i j}=\frac{\operatorname{sig}_{P-\left\{r_{i}\right\}}\left(r_{i}\right)}{\operatorname{sig}_{P-\left\{r_{j}\right\}}\left(r_{j}\right)} \geq 0 \quad, \mathrm{i}, \mathrm{j}=1,2, \cdots, \mathrm{n}
$$

Let $\mathrm{C}$ is the matrix combined $\mathrm{A}$ and $\mathrm{B}, \mathrm{C}=(\operatorname{cij}) \mathrm{n} \times \mathrm{n}$, cij $\geqslant 0$, establish the most optimal model:

$\min \{[\mu((\mathrm{C}-\mathrm{A}) 2 / 2)+(1-\mu)((\mathrm{C}-\mathrm{B}) 2 / 2)]\}, 0 \leqslant \mu \leqslant 1$

The formula has a unique solution [13]:

$\mathrm{C}=\mu \mathrm{A}+(1-\mu) \mathrm{B}=\mu($ aij $) \mathrm{n} \times \mathrm{n}+(1-\mu)(\mathrm{bij}) \mathrm{n} \times \mathrm{n}$

Proof:

Make Lagrange function $\mathrm{L}(\mathrm{C}, \lambda)=[\mu((\mathrm{C}-\mathrm{A}) 2 / 2)+(1-$ $\mu)((\mathrm{C}-\mathrm{B}) 2 / 2)]+\lambda(\mathrm{C}-1), \quad$ there is $\mathrm{L}(\omega \mathrm{C}, \quad \lambda)=[\mu((\omega \mathrm{C}-$ $\omega \mathrm{A}) 2 / 2)+(1-\mu)((\omega \mathrm{C}-\omega \mathrm{B}) 2 / 2)]+\lambda(\omega \mathrm{C}-1)$. Where, $\omega \mathrm{A}, \omega \mathrm{B}, \omega \mathrm{C}$ are the weight vectors normalized of matrix $A, B, C$ there is:

$$
\begin{aligned}
& \sum_{i=1}^{n} \omega_{A}=\sum_{i=1}^{n} \omega_{B}=\sum_{i=1}^{n} \omega_{C}=1, \mathrm{i}=1,2, \cdots, \mathrm{n} \\
& \quad \text { Let } \partial_{\mathrm{L} /} \partial_{\mathrm{C}=0,} \sum_{i=1}^{n} \omega_{C}-1=0, \text { getting equations: } \\
& \left\{\begin{array}{l}
\mu\left(\omega_{C}-\omega_{A}\right)+(1-\mu)\left(\omega_{C}-\omega_{B}\right)=0 \\
\sum_{i=1}^{n} \omega_{C}-1=0
\end{array}\right.
\end{aligned}
$$

The solution is $\omega \mathrm{C}=\mu \omega \mathrm{A}+(1-\mu) \omega \mathrm{B}$, so $\mathrm{C}=\mu \mathrm{A}+(1-$ $\mu) B=\mu($ aij $) n \times n+(1-\mu)($ bij $) n \times n$.

In the actual calculation, we just need to find the weight vector $\omega \mathrm{C}$ of combined judgment matrix $\mathrm{C}$, each element in $\omega \mathrm{C}$ is weight of the corresponding index. $\omega \mathrm{C}=\mu \omega \mathrm{A}+(1-$ $\mu) \omega B$ can be known from the above proof.

\section{EXAMPLE AND CONTRAST}

Take selecting a certain type of household appliance for example, factors to be considered are power (a1), price (a2), security (a3), appearance (a4), human (a5).

First, calculate the weight of each factor by AHP. Compare the five factors a1, a2, a3, a4, a5 with each other to get the judgment matrix $\mathrm{A}$ :

$A=\left[\begin{array}{ccccc}1 & 1 & 1 / 1.3161 & 1 & 1.3161 \\ 1 & 1 & 1 / 1.3161 & 1.3161 & 1 \\ 1.3161 & 1.3161 & 1 & 3 & 1 \\ 1 & 1 / 1.3161 & 1 / 3 & 1 & 1 / 1.3161 \\ 1 / 1.3161 & 1 & 1 & 1.3161 & 1\end{array}\right]$

The feature root and the eigenvector of Matrix A calculated out by Matlab program is: $\lambda=5.101$, $\omega=(0.427,0.419,0.603,0.310,0.428)$, normalize it and get $\omega \mathrm{A}=(0.195,0.192,0.276,0.141,0.196) . \quad \mathrm{CI}=(\lambda-n) /(\mathrm{n}-$ $1)=(5.101-5) /(5-1)=0.025, \mathrm{CI} / \mathrm{RI}=0.025 / 1.12=0.022<0.1$, so A can pass the consistency test.

And then construct an objective judgment matrix, respectively use a1, a2, a3, a4, a5 as condition attributes $\mathrm{C}$ (rule layer), $\mathrm{f}$ is the decision attribute, corresponding to decision attribute D (target level). Performance parameters of a certain type of home appliances can got from the relevant data that manufacturer and the country published from, and its range is $\{1,2,3\}$, the meaning of the attribute values correspond to three grades: good (high), middling, general, here 10 brands was selected as the object set $U$, the decision table shown in Table.3.

Write $U=\{1,2,3,4,5,6,7,8,9,10\}$, we got:

$\operatorname{Ind}(\mathrm{P})=\{\{1\},\{2\},\{3\},\{4\},\{5\},\{6\},\{7\},\{8\},\{9\},\{10\}\}$;

$\operatorname{Ind}(\mathrm{P}-\{1\})=\{\{1\},\{2\},\{3\},\{4,5,6\},\{7\},\{8\},\{9\},\{10\}\}$;

$\operatorname{Ind}(\mathrm{P}-\{2\})=\{\{1,7\},\{2,6\},\{3,8\}, 4,5,9,10\}$;

Ind $(\mathrm{P}-$

$\{3\})=\{\{1\},\{2\},\{3\},\{4\},\{5\},\{6\},\{7\},\{8\},\{9,10\}\}$; $\operatorname{Ind}(\mathrm{P}-\{4\})=\{\{1,2\},\{3\},\{4\},\{5\},\{6,7\},\{8\},\{9\},\{10\}\} ;$ $\operatorname{Ind}(\mathrm{P}-\{5\})=\{\{1\},\{2\},\{3\},\{4,10\},\{5\},\{6\},\{7\},\{8\},\{9\}\}$.

Take them into (1) and (2):

sigp $-\{1\}(1)=\mathrm{I}(\mathrm{P})-\mathrm{I}(\mathrm{P}-\{1\})=64 / 100$; 
sigp $-\{2\}(2)=\mathrm{I}(\mathrm{P})-\mathrm{I}(\mathrm{P}-\{2\})=49 / 100$;

sigp $-\{3\}(3)=\mathrm{I}(\mathrm{P})-\mathrm{I}(\mathrm{P}-\{3\})=81 / 100$;

sigp $-\{4\}(4)=I(P)-I(P-\{4\})=64 / 100$;

sigp $-\{5\}(5)=\mathrm{I}(\mathrm{P})-\mathrm{I}(\mathrm{P}-\{5\})=81 / 100$.

Compare the attribute importance with each other to get the object judgment matrix B:

$$
B=\left[\begin{array}{ccccc}
1 & 64 / 49 & 64 / 81 & 1 & 64 / 81 \\
49 / 64 & 1 & 49 / 81 & 49 / 64 & 49 / 81 \\
81 / 64 & 81 / 49 & 1 & 81 / 64 & 1 \\
1 & 64 / 49 & 64 / 81 & 1 & 64 / 81 \\
81 / 64 & 81 / 49 & 1 & 81 / 64 & 1
\end{array}\right]
$$

The feature root and the eigenvector of Matrix B calculated out by Matlab program is: $\omega=(0.416,0.318$, $0.526,0.416,0.526)$, normalize it and get $\omega \mathrm{B}=(0.189,0.144$, $0.239,0.189,0.239)$

Consider subjective and objective factors comprehensively, and take $\mu=0.5$, then $\omega \mathrm{C}=\mu \omega \mathrm{A}+(1-$

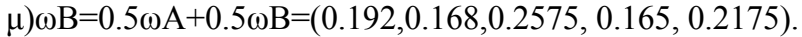

Table IV shows that AHP reflect the actual situation to some extent, but the weight emphasis too much on experience and subjective factors, and difference between weight of each factor is too large; the weight based on rough set put too much focus on the objective conditions, ignoring some subjective factors, such as for high-income people the conclusion is the same, but the weight of price factor is too small for low-income people; the weight got by the method of this paper combined subjective and objective factors, by the proposed method are integrated to determine the weight matrix the subjective and objective factors, and the results of the weight of each factor is close, clearly this index weighting method is more reasonable. Therefore, the proposed method is feasible, can improve the accuracy of decision-making, and have some practical value.

\section{SUMMARIES}

In summary, the subjective judgment matrix based on AHP to is derived from expert experience; the objective judgment matrix based on rough set reflects inherent link between attributes; this paper combined subjective judgment matrix and objective judgment matrix into a new matrix, and proposed a comprehensive index weighting method on this base. The example showed that the method is effective and feasible.

\section{REFERENCES}

[1] Wu Junqing; Zheng Muqi; Zhang Zhixing. Theory and Method of Performance Evaluation[M], 1992.9.

[2] Cheng Jilin. Excellent Selection Theory of Large-scale System Test and Application[M], Shanghai: Shanghai Science and Technology Press, 2002.

[3] Guo Yajun. Comprehensive Evaluation Theory and Method[M], Beijing: Science Press, 2002.

[4] ROSSIGNACR, ea. Multi-Resolution 3D Approximations for Rendering Complex Scenes[J], Technical Report RC17697, IBM Research Division, 1993.

[5] Xue Qing; Z.G.-h.e.a. The study of C4ISR System Effectiveness Evaluation Based on Information Entropy in the Network Centric Warfare[J], in IHMSC09. 2010. Hang Zhou.

[6] Qiu Wanhua. Management Decision-making and Application of Entropy study[M], Beijing: Mechanical Industry Press, 2002.

[7] Qin Shoukang. Comprehensive Evaluation Principle and Application[M], Beijing: Electronic Industry Press, 2003.

[8] CIGNONIP, ea. A Comparison of Mesh Simplification Algorithms[J], Computer \& Graphics, 1998. 22 (1): p. 37-54.

[9] Xu Shubai. AHP theory[M], Tianjin: Tianjin University Press, 1993

[10] Hou Yueheng; Shen Dejia. Comparison of Index Scale With Several Other Scales[J], Systems Engineering Theory \& Practice, 1996, (5) : $18-20$.

[11] Wang Biao; Duan Chanlun; Wu Hao. Application on Rough set and Fuzzy set[M], Beijing: Electronic Industry Press, 2008:38-154.

[12] Wu Jinpei; Sun Deshan. Modern Data Analysis[M], Beijing: Mechanical Industry Press, 2006.6.

[13] Zhong Jiaming; Li Dingfang. Comprehensive evaluation model integrated based on rough set and analytic hierarchy process[J], Engineering Journal of Wuhan University, 2008,41 (4): 126-130. 
TABLE I. THE INDEX SCALE

\begin{tabular}{|l|l|l|}
\hline \multicolumn{2}{|c|}{ Scale } & \\
\hline $9^{0}$ & 1 & A and B are equally important \\
\hline $9^{1 / 8}$ & 1.3161 & A is little important than B \\
\hline $9^{2 / 8}$ & 1.7321 & A is important than B \\
\hline $9^{4 / 8}$ & 3 & A is significantly important than B \\
\hline $9^{6 / 8}$ & 5.1966 & A is highly important than B \\
\hline $9^{8 / 8}$ & 9 & A is vital than B \\
\hline $\begin{array}{l}\text { The reciprocal of the } \\
\text { above scale }\end{array}$ & the scale of Element $i$ to $j$ is $a_{i j}$, contrarily is $a_{j i}$ \\
\hline
\end{tabular}

TABLE II. AVERAGE RANDOM CONSISTENCY INDEX

\begin{tabular}{|l|l|l|l|l|l|}
\hline order & $\mathbf{1}$ & $\mathbf{2}$ & $\mathbf{3}$ & $\mathbf{4}$ & $\mathbf{5}$ \\
\hline RI & 0 & 0 & 0.52 & 0.89 & 1.12 \\
\hline
\end{tabular}

\begin{tabular}{|l|l|l|l|l|l|}
\hline order & $\mathbf{6}$ & $\mathbf{7}$ & $\mathbf{8}$ & $\mathbf{9}$ & $\mathbf{1 0}$ \\
\hline RI & 1.26 & 1.36 & 1.41 & 1.46 & 1.49 \\
\hline
\end{tabular}

\begin{tabular}{|l|l|l|l|l|l|}
\hline order & $\mathbf{1 1}$ & $\mathbf{1 2}$ & $\mathbf{1 3}$ & $\mathbf{1 4}$ & $\mathbf{1 5}$ \\
\hline RI & 1.52 & 1.54 & 1.56 & 1.58 & 1.59 \\
\hline
\end{tabular}

TABLE III. DECISION TABLE OF SELECTING A CERTAIN TYPE OF HOUSEHOLD APPLIANCE

\begin{tabular}{|l|l|l|l|l|l|l|}
\hline \multirow{2}{*}{$\mathbf{U}$} & \multicolumn{7}{|c|}{$\mathbf{C}$} & $\mathbf{D}$ \\
\cline { 2 - 7 } & $\mathbf{a}_{1}$ & $\mathbf{a}_{2}$ & $\mathbf{a}_{3}$ & $\mathbf{a}_{4}$ & $\mathbf{a}_{5}$ & $\mathbf{f}$ \\
\hline 1 & 1 & 1 & 3 & 1 & 2 & 1 \\
\hline 2 & 1 & 1 & 3 & 3 & 2 & 2 \\
\hline 3 & 2 & 1 & 1 & 2 & 1 & 1 \\
\hline 4 & 2 & 2 & 3 & 3 & 2 & 2 \\
\hline 5 & 3 & 2 & 3 & 3 & 2 & 3 \\
\hline 6 & 1 & 2 & 3 & 3 & 2 & 1 \\
\hline 7 & 1 & 2 & 3 & 1 & 2 & 2 \\
\hline 8 & 2 & 3 & 1 & 2 & 1 & 2 \\
\hline 9 & 2 & 2 & 2 & 3 & 3 & 2 \\
\hline 10 & 2 & 2 & 3 & 3 & 3 & 3 \\
\hline
\end{tabular}

TABLE IV. TABLE OF SELECTING A CERTAIN TYPE OF HOUSEHOLD APPLIANCE

\begin{tabular}{|l|l|l|l|l|l|}
\hline \multicolumn{1}{|c|}{ Methods } & a1 & a2 & $\mathbf{a 3}$ & $\mathbf{a 4}$ & $\mathbf{a 5}$ \\
\hline AHP & 0.195 & 0.192 & 0.276 & 0.141 & 0.196 \\
\hline taxis & 3 & 4 & 1 & 5 & 2 \\
\hline RS & 0.189 & 0.144 & 0.239 & 0.189 & 0.239 \\
\hline taxis & 3 & 5 & 1 & 3 & 1 \\
\hline $\begin{array}{l}\text { Comprehensive } \\
\text { method }\end{array}$ & 0.192 & 0.168 & 0.2575 & 0.165 & 0.2175 \\
\hline taxis & 3 & 4 & 1 & 5 & 2 \\
\hline
\end{tabular}

